Filol. Linguíst. Port., São Paulo, v. 17, n. 1, p. 57-73, jan./jun. 2015 http://dx.doi.org/10.11606/issn.2176-9419.v17i1p57-73

\title{
Fundamentos para o estudo da oralidade na escrita
}

\section{Fundaments for the study of orality in written language}

José Gaston Hilgert *

Universidade Presbiteriana Mackenzie, São Paulo, São Paulo, Brasil

\begin{abstract}
Resumo: No presente artigo introduzem-se reflexôes sobre a produção de efeitos de oralidade em textos escritos à luz de fundamentos da enunciaçáo. Nesse contexto teórico, mostra-se que não se deve partir de uma identificação aleatória de recursos lexicais e sintáticos, figurativos e temáticos, estilísticos ou retóricos para a compreensão da oralidade na escrita. Importa, antes de mais nada, identificar o cenário interativo em que esses recursos de linguagem se manifestam. O cenário interativo ou cenário de interação é configurado pela a relação narrador/narratário revelada no texto. Se essa relação se realiza por meio da interação de um $e u$ (narrador) com um você (narratário), explícitos ou implícitos, tem-se nele instituído o princípio básico do diálogo, da conversa, que define a condiçấo de proximidade dos interlocutores e, portanto, o cenário interativo propício ao uso dos recursos de oralidade. Na medida, porém, em que essa relação se realiza na forma de um narrador em terceira pessoa que se dirige a um leitor implícito, estabelece-se o cenário do distanciamento, no qual recursos que evoquem a oralidade não cabem ou, se ocorrem, assumem função específica. Este texto vai, então, dar especial atenção ao cenário interativo constituído pela interaçáo eu/você, mostrando, em diferentes exemplos, os traços de oralidade determinados por ela e, também, os variados graus de proximidade que ela, por suas variadas formas de manifestação, pode revelar.
\end{abstract}

Palavras-chave: Cenário de interação. Ensino. Enunciação. Escrita. Oralidade.

\footnotetext{
* Professor do Curso de Letras e do Programa de Pós-Graduação em Letras (Mestrado e Doutorado) da Universidade Presbiteriana Mackenzie - UPM, São Paulo, São Paulo, Brasil; bolsista de Produtividade em Pesquisa do CNPq; gastonh@uol.com.br
} 


\begin{abstract}
In this paper, we put forth some reflections upon the production of effects of orality in written texts in light of the fundaments of enunciation. In this theoretical context, we show that the study of orality in written language should not depart from the random identification of lexical and syntactic, figurative and thematic, stylistic or rhetoric resources. What matters is the identification of the interactive scenario in which these linguistic resources are manifested. The interactive scenario is configured by the relationship between narrator/narratee revealed in the text. If this relation takes place by means of the interaction between an $I$ (narrator) and a you (narratee), either explicit or implicit, then it is instituted, in this scenario, the basic principle of dialog, of conversation, which defines the proximity condition of the interlocutors and, therefore, the interactive scenario favorable to the use of orality resources. When this relation, however, takes place in the form of a third person narrator who addresses him/herself to an implicit reader, the scenario of distancing is installed, in which orality resources may be unfit or, if they occur, they may have specific functions. This text addresses special attention to the interactive scenario set by the interaction between I/you, showing, in different examples, traits of orality determined by such interaction, and also the various degrees of proximity that this interaction may reveal in its various manifestations.
\end{abstract}

Keywords: Interactive scenario. Teaching. Enunciation. Orality. Written language.

\title{
1 INTRODUÇÃO
}

No trabalho de análise e interpretação de textos na escola, seja na perspectiva literária, seja em outra, a abordagem da oralidade na escrita limita-se, em geral, à identificação de elementos do léxico ou da sintaxe que, por percepção subjetiva dos leitores, seriam recorrentes em manifestaçôes da fala. Não que tais constataçôes sejam necessariamente equivocadas ou levem a intepretações não autorizadas nos textos. Elas costumam ser, no entanto, empíricas, feitas com critérios vagos e, por isso, facilmente contestáveis. É comum, por exemplo, que em determinado texto escrito seja atribuído a certo uso um caráter oral, e que em outro contexto essa atribuição não seja possível para o mesmo recurso de linguagem. A que se deve essa variação? Como explicá-la? As respostas a essas perguntas são em geral múltiplas, dispersas, quando não individuais, ou seja, baseadas na "opinião" de cada analista.

Hilgert JG. Fundamentos para o estudo da oralidade na escrita 
A questão primeira não é, então, identificar, aleatoriamente, recursos lexicais e sintáticos, figurativos e temáticos, estilísticos ou retóricos que produzem efeito de oralidade nos textos. A nosso ver, o que importa, antes de mais nada, é definir o cenário interativo em que os recursos de linguagem em observação se manifestam. Por cenário interativo ou cenário de interação entendemos, por ora (adiante aprofundaremos essa noção), a relação enunciador/enunciatário - instância pressuposta para a existência de qualquer enunciado - projetada no texto na relação narrador/narratário.

Sabemos que a enunciação é o ato de um enunciador, em interação com um enunciatário, produzir o enunciado, ou seja, o texto. Em relação a este, a enunciação vem sempre pressuposta, ou seja, o texto tem existência na medida em que alguém o enunciou antes. Portanto, o enunciador e o enunciatário não se manifestam mais no texto, mas nele vêm representados, respectivamente, pelo narrador e pelo narratário.

Caso no texto, então, a relação narrador/narratário se estabeleça pela interação de um eu (narrador) com um você (narratário), tem-se nele instituído o princípio básico do diálogo, da conversa, que define a condição de proximidade dos interlocutores e, portanto, o cenário interativo propício ao uso dos recursos de oralidade. $\mathrm{Na}$ medida, porém, em que essa relação se realiza na forma de um narrador em terceira pessoa que se dirige a um leitor implícito, estabelece-se o cenário do distanciamento, no qual recursos que evoquem a oralidade não cabem ou, se ocorrem, causam estranheza.

$\mathrm{Na}$ linha dessas consideraçóes, visa o presente estudo a introduzir reflexóes a propósito da produção de efeitos de oralidade em textos escritos à luz de fundamentos da enunciação. Em outras palavras, pretendemos focalizar a oralidade na escrita num âmbito teórico em que os sentidos do texto e no texto são concebidos e explicados como produtos da enunciação. Destinamos essas reflexóes aos professores de língua portuguesa e de literatura, do Ensino Fundamental e Médio, a fim de que elas lhes sirvam de subsídio para melhor explorar com os seus alunos os sentidos nos textos em diferentes perspectivas, mas, particularmente aqueles produzidos pelos recursos à oralidade.

\section{CARACTERIZAÇÃO ESPECÍFICA DA ENUNCIAÇÃO CONVERSACIONAL}

Quando se fala em oralidade, evoca-se imediatamente a comunicação na fala, particularmente a interação face a face, a conversa, que é a interação falada prototípica. Ela acontece quando, ao menos, dois indivíduos se encontram e, a partir 
desse encontro, sem preparação prévia, iniciam um diálogo sobre um tema de interesse comum naquele momento. $\mathrm{Na}$ interação, eles alternam, em situação face a face, os papéis de falante e ouvinte, no desenvolvimento de um determinado tema. Nessas condições, os propósitos comunicativos de um em relação ao outro não vêm anteriormente planejados. Quando muito, o falante que desencadeia a conversa tem uma vaga noção do que vai dizer ao proceder ao turno ${ }^{1}$. E, a partir daí, a interação se desdobra por determinaçóes mútuas, seguindo destino incerto, que só se definirá em sua evolução no âmbito da prática social que a move. Isso quer dizer que é no próprio desdobramento da enunciação que o planejamento da interação se realiza, e este só se completa com a enunciação concluída. Essa simultaneidade do "dizer" e com o "que dizer", nas condições sempre renovadas da dinâmica contextual, deixa uma série de marcas responsáveis pela caracterização específica da enunciação conversacional e, portanto, pela distinção entre o "texto" conversacional e o texto escrito.

Abordar essa distinção é um trabalho importante no estudo da fala, pois dá às características desta especial relevo. É verdade que, do ponto de vista da natureza enunciativa, os dois tipos de enunciação (na fala e na escrita) mais apresentam identidades e afinidades do que grandes diferenças, conforme apontaremos a seguir. As distinções vão se revelar mesmo no âmbito dos enunciados, isto é, dos produtos da enunciação.

Quando se analisa o produto final de uma interação falada, isto é, quando se ouve a gravação e, simultaneamente, se acompanha sua transcrição, observa-se que, nesse enunciado, vêm registradas, em princípio, todas as operaçóes realizadas pelos interlocutores na progressividade da enunciação, no contexto e nas circunstâncias em que esta se realizou. O registro detalhado dos procedimentos da produção interativa constitui o principal traço distintivo do "texto" falado. Já no texto escrito, grande parte das atividades de enunciação vem nele apagadas.

Explicitemos essa distinção no seguinte segmento conversacional:

DOC vocês disseram que a nossa moda sofre influência estrangeira ( ) como vocês justificariam essa influência? ...

L1 bom ... isso é normal ... tudo aquilo que se consome que se vê ... tem uma uma:: ... uma uma ...

\section{L2 uma origem}

1 Numa conversa, os falantes alternam suas falas. À vez de fala de cada um dá-se o nome de turno. A passagem conversacional que vem logo a seguir, por exemplo, desdobra-se em quatro turnos. 
L1 uma origem euro/ eu não vou dizer europeia eh estrangeira ... sempre de países ou de regióes e zonas mais desenvolvidas (Hilgert, 2009, p. 165)

Em resposta à pergunta de DOC, verifica-se, ao final do primeiro turno de L1, uma clara sinalização, por meio da repetição do artigo "uma" (quatro vezes), acentuada por alongamento e pausas, de que o falante está à busca de u ma formulação adequada para o que intenta dizer. No dizer Blanche-Benveniste (1990, p. 25), explicita-se, no desdobramento da interlocução, um "trabalho de denominação". O ouvinte, L2, percebendo que seu interlocutor não está chegando a bom termo nessa busca, sugere-lhe uma solução: "uma origem". L1, então, mesmo antes de L 2 concluir sua sugestão, intervém, acolhendo-a como sendo a formulação própria para a otimizaçâo de seu enunciado, como podemos verificar na última intervenção de L1.

É da natureza do "texto" falado que todo esse trabalho de busca da formulação adequada fique registrado, fixando-se, assim, no enunciado o aqui e o agora da enunciação. Embora esse trabalho também possa ser inerente à enunciação escrita (nela igualmente são recorrentes hesitaçôes nas escolhas lexicais e nas formulações sintáticas, interrupções, reinícios, correções, adequaçōes, reformulaçôes ${ }^{2}$ ), ele vem, em princípio, apagado no enunciado, no qual só se registra o produto final. Nesse sentido, a interação aqui em foco, para fins de comunicação escrita, poderia ficar assim:

DOC vocês disseram que a nossa moda sofre influência estrangeira. Como vocês justificariam essa influência?

L1 Bom, isso é normal. Tudo aquilo que se consome, que se vê tem origem, não digo europeia, mas estrangeira, sempre de países ou de regiốes e zonas mais desenvolvidas.

É evidente que, nessa reformulação para a escrita, não haveria razão para o turno colaborativo de L2, uma vez que ele só se justifica por força da hesitação de L1 na definição lexical, em situação face a face, hesitação não registrada na versão final do texto escrito, mas não necessariamente ausente de seu processo de enunciação. Em outras palavras, é bem possível que, na formulação escrita do texto, o termo desejado também não tenha ocorrido ao enunciador de forma imediata e fluente, mas só depois de um certo trabalho consigo mesmo de busca e definição.

2 Não ocorrem, é claro, intervençôes do interlocutor (do leitor) em razão das condições de produção do texto escrito.

Hilgert JG. Fundamentos para o estudo da oralidade na escrita 
Em resumo, a natureza do "texto" falado (do enunciado) consiste no fato de ele explicitar seu processo de enunciação, expondo as estratégias do enunciador (do eu) para fazer-se compreender e, assim, persuadir o seu enunciatário (o tu), aqui e agora, em situação face a face, isto é, em situação de proximidade. O texto escrito, pelas próprias condiçôes de produção, marcadas pelo distanciamento entre enunciador (autor) e enunciatário (leitor), não expõe de forma tão explícita e minuciosa as marcas da enunciação, o que não significa que textos escritos não possam evidenciar relaçóes de proximidade entre destinador e destinatário, conforme veremos.

\section{ORALIDADE E PROXIMIDADE NA ESCRITA COMO EFEITOS DE DISCURSO}

Focalizar os traços que produzem efeitos de proximidade em textos escritos é estender a abordagem da oralidade também à escrita. Em textos escritos, não se apresentam, obviamente, conforme vimos, as marcas de oralidade inerentes a u ma conversa, como a alternância de turnos, a negociaçáo aqui e agora da melhor formulação, certas repetiçôes e paráfrases, interrupçóes sintáticas, recomeços, hesitações e outras similares, que são características próprias de uma enunciação em que os interlocutores enunciam face a face, isto é, em que tempo e espaço de produção e recepção coincidem. Na escrita, a oralidade é de ordem conceptual ${ }^{3}$, na medida em que o texto, no todo ou em alguma de suas partes, é reconhecido pelo usuário da língua como tendo configuração oral em razão de certos recursos e estratégias usados em sua construção. Em outras palavras, esses recursos e estratégias, por evocarem elementos das interaçóes faladas, produzem no texto escrito efeitos de oralidade e, por isso, efeitos de proximidade. Portanto, a percepção de

3 Koch e Oesterreicher (1985, 1990, 1994 e 2007) e Marcuschi (2001) distinguem a oralidade e a escrita mediais da oralidade e da escrita conceptuais. Do ponto de vista medial, é oral todo texto que se apresenta em forma fônica, não importando se é uma conversa entre amigos ou uma conferência científica; e é escrito o texto apresentado graficamente, que tanto pode ser, por exemplo, uma interação do WhatsApp (por escrito) quanto um editorial de jornal. Já na perspectiva conceptual, um texto é marcado pela oralidade, quando, na percepção do usuário da língua, ele se identifica com a fala ou apresenta traços que lembrem uma manifestação falada, não importando se, medialmente, o texto seja escrito ou falado. Assim, a conversa entre amigos é medial e conceptualmente falada, e a interação pelo WhatsApp é medialmente escrita, mas conceptualmente falada. O mesmo raciocínio vale para a escrituralidade: a conferência científica é medialmente falada, mas conceptualmente escrita, pois assume um modo de ser dos textos tipicamente escritos; já o editorial de jornal, além de medialmente escrito, também o é do ponto de vista conceptual.

Hilgert JG. Fundamentos para o estudo da oralidade na escrita 
proximidade entre destinador e destinatário que as marcas de oralidade no texto escrito produzem não deve ser concebida como decorrência de uma proximidade real entre os interlocutores, mas sim como um efeito de discurso resultante de estratégias de construção do texto.

Lançar luz sobre essas estratégias significa explicitar referências teóricas que possibilitem compreender as marcas de oralidade em textos escritos na perspectiva de uma teoria de texto. É o que aqui tentaremos fazer, concebendo o texto como um produto da enunciação.

\section{A ORALIDADE NA ESCRITA DO PONTO DE VISTA DA ENUNCIAÇÃO}

Quando definimos um objeto de estudo linguístico-discursivo, voltamo-nos a um produto da enunciação, ao enunciado, ou seja, ao texto. É nele - no texto - que o processo da enunciação (o ato de produzir o texto) vem projetado. E, portanto, é pelo texto que se tem acesso às operaçóes realizadoras da enunciação. ${ }^{4}$

Como já dissemos na introdução, a enunciação se realiza na interação entre um enunciador e um enunciatário, entre um eu e um $t u$. Segundo Tatit (2002, p. 205),

o conceito de enunciador deve ser tomado como uma categoria abstrata, cujo preenchimento, numa manifestação específica, faz emergir o que conhecemos como autor, falante, artista, poeta, etc.; a noção de enunciatário, igualmente, define-se como categoria por meio da qual se manifestam leitores e fruidores de maneira geral.

Não se deve, no entanto, entender que o sujeito da enunciação de um texto seja unicamente o enunciador. Também o enunciatário enuncia, assumindo um papel de co-enunciador. Na explicação de Fiorin (2003, p. 163), "o enunciatário, como filtro e instância pressuposta no ato de enunciar, é também sujeito produtor do discurso, pois o enunciador, ao produzir um enunciado, leva em conta o enunciatário a quem ele se dirige". Portanto, a instância de sujeito da enunciação é assumida por ambos, o enunciador $e u$ e enunciatário $t u$. O eu, sempre determinado pelo $t u$, necessariamente enuncia num tempo agora e num espaço aqui. $\mathrm{O}$

4 Segundo Kerbrat-Orecchioni (1980: 30), "na impossibilidade de poder estudar diretamente o ato de produção, (...) busca-se identificar e descrever os traços do ato no produto". 
eu (a pessoa), o agora (o tempo) e o aqui (o espaço) são as categorias da enunciação e, como tais, os fatores constituintes de todo e qualquer ato da enunciação.

Ao enunciar, o enunciador projeta no enunciado, de forma calculada ou não, suas escolhas, movido pelas circunstâncias da comunicação em curso e por seus propósitos em relaçáo a ela. Nessas escolhas, há as, digamos, de primeira ordem e as de segunda ordem.

As escolhas de primeira ordem definem dois cenários de interação distintos; as de segunda ordem decorrem da configuração específica de cada um desses cenários. Para definir cenário de interação, inspiramo-nos no conceito de "cenografia", de Maingueneau (2006, p. 67):

A cenografia é a cena de fala ${ }^{5}$ que o discurso pressupóe para poder ser enunciado e que, por sua vez, deve validar através de sua própria enunciação: qualquer discurso, por seu próprio desenvolvimento, pretende instituir a situação de enunciação que o torna pertinente.

$\mathrm{Na}$ verdade, a denominação cenário de interação corresponde ao que o autor chama de "cena de fala". Só não optamos, neste texto, por essa denominaçáo de Maingueneau, para evitar uma eventual leitura equivocada que restringisse "cena de fala" à expressão falada, já que aqui estamo-nos referindo à enunciação em geral, tanto em interaçóes faladas quanto em escritas.

Dito isso, fixemo-nos, inicialmente, nas escolhas de primeira ordem. Como dissemos, por meio delas o enunciador pode definir dois cenários de interação distintos: um cenário enunciativo ou um cenário enuncivo. $\mathrm{O}$ cenário enunciativo se caracteriza pela projeção das marcas da enunciação (eu/tu, agora e aqui) no enunciado, e o enuncivo pelo apagamento dessas marcas no enunciado. A opção por um ou outro desses cenários determina dois tipos de textos: no primeiro caso, os textos enunciativos, identificados pela enunciação enunciada; no segundo, os textos enuncivos, caracterizados pelo enunciado enunciado.

Distingamos esses cenários de interação nos seguintes textos:

Texto 1

\section{Por que as girafas fedem? ${ }^{6}$}

5 Destaque do autor.

6 O texto é de Gisele Lopes e está publicado em http://chc.cienciahoje.uol.com.br/por-que-asgirafas-fedem/ (Acesso em 25. 6. 2014). 


\section{Compostos presentes no pelo desses animais ajudam a mantê-los livres de doenças!}

Quem já foi ao zoológico e viu as girafas deve ter reparado no "cheirinho" que elas têm. Se você achou que era o tratador que não estava cuidando delas direito, saiba que esse mau-cheiro não tem nada a ver com banho. Ele é característico desses animais e pode ser sentido a dezenas de metros de distância. Mas você sabe por que as girafas fedem?

Essa pergunta foi um enigma para os cientistas durante muito tempo, mas agora o biólogo William Wood, da Universidade Estadual de Humboldt, nos Estados Unidos, acredita ter achado a resposta para ela. William estudou alguns pelos de girafas em seu laboratório e descobriu que eles possuíam diversas substâncias químicas, algumas delas iguais a outras encontradas nas fezes humanas - o que explica o mau cheiro. Mas tudo tem um lado bom: apesar de as substâncias serem fedorentas, elas são muito úteis às girafas, pois mantêm afastados os parasitas e ainda matam os micróbios.

\section{(...)}

Mas lembre-se bem: o mau-cheiro das girafas pode trazer benefícios para elas, mas isso não significa que vá fazer bem pra você também! Portanto, nem adianta dizer pra sua mãe que leu no site da Ciência Hoje das Crianças que o fedor protege, porque o exemplo das girafas náo é desculpa pra fugir do banho... [Gisele Lopes] (http://chc.cienciahoje.uol.com.br/por-que-as-girafas-fedem/ Acesso em 01. 10. 2014)

\section{Texto 2}

Enquanto uma forma linguística for apenas um sinal e for percebida pelo receptor somente como tal, ela não terá para ele nenhum valor linguístico. A pura "sinalidade" não existe, mesmo nas primeiras fases de aquisição da linguagem. Até mesmo ali, a forma é orientada pelo contexto, já constitui um signo, embora o componente de "sinalidade" e de identificação que lhe é correlata seja real. Assim, o elemento que torna a forma linguística um signo náo é sua identidade como sinal, mas sua mobilidade específica; da mesma forma que aquilo que constitui a descodificação da forma linguística não é o reconhecimento do sinal, mas a compreensão da palavra no seu sentido particular, isto é, a apreensão da orientação que é conferida à palavra por um contexto e uma situação precisos, uma orientação no sentido da evolução e não do imobilismo (Bakhtin, 2010, p. 97).

Ambos os textos são produtos da enunciação de um $e$, que, em interação com um $t u$, enunciou num tempo agora e num espaço aqui. Essa é a natureza de 
todo ato de enunciação. No primeiro desses dois textos, essas marcas da enunciação vêm projetadas no texto, na medida em que um narrador $e u$ (implícito) ${ }^{7}$ se dirige a um narratário você. O cenário de interação projetado no texto é, entáo, enunciativo, configurado pela relação $e u$-você, que lembra as interaçóes simétricas face a face, marcadas pela proximidade entre os interlocutores.

$\mathrm{O}$ segundo texto tem as marcas de sua enunciação apagadas. $\mathrm{O}$ narrador é alguém que fala, um ele, que se dirige a um narratário-leitor não explicitado, fato que evidentemente evoca um cenário de interação enuncivo, produzindo um efeito de distanciamento entre os interlocutores.

É o primeiro cenário que nos importa nas reflexóes do presente texto, pois é ele que estabelece as condiçóes de princípio para a emergência de efeitos de sentido de oralidade. Sobre o segundo cenário, só faremos breves comentários ao final do texto.

Quando o enunciador opta pela primeira escolha, vem projetado no texto, entáo, o cenário interativo caracterizado, do ponto de vista da categoria pessoa, pela interação entre um narrador eu e um narratário $t u$.

Segundo Barros (2002, p. 23), a instância narrador-narratário explicitada no texto pela relação $e u-t u$ (você), ou seja, o cenário de interaçáo enunciativo

produz, por excelência, os efeitos de aproximação da enunciação, de subjetividade, de relaçáo dialógica ou recíproca entre os sujeitos. (...). O uso da relação eu e você caracteriza, por isso mesmo, interações informais, íntimas e espontâneas, na conversação face a face ideal.

Essa caracterização decorre justamente do fato de que a relação $e u$-tu (você) no texto escrito evoca a interaçấo entre falante e ouvinte na conversa, na qual eles alternam, em situação face a face, o papel de $e u$ e de $t u$. Segundo a mesma autora e obra, "destinador e destinatário se colocam no mesmo quadro enunciativo" (p. 23), do que resulta uma simetria interativa.

Um texto, portanto, em que o narrador eu se dirige a um narratário tu (você), evoca, em princípio, o cenário da interação face a face, da conversa, graças ao qual se instala nesse texto a condição que determina a escolha de outros recursos de linguagem - as escolhas de segunda ordem - que concorrerão para a produção de efeitos de sentido de oralidade e, por conseguinte, de proximidade entre autor e leitor.

7 Esse narrador não vem explicitado no texto pelo pronome eu ou pela marcação da forma verbal, mas ele está implícito no fato da menção do destinatário você, pois somente um eu pode dizer você. 
Analisemos alguns textos nesse sentido:

\section{Texto 3}

Heloísa: As cartas que te envio já se vão tornando maçadoras, não é verdade? Ficas assustada, certamente, com a exuberância de tinta gasta, de papel inutilizado, e pensas, aflita, no trabalho que terás para dar resposta a tanta coisa. Não te preocupes. Não precisas consignar o que te mando num registro em que escritures com paciência o assunto, a data, o número das palavras. Escreve-me quando tiveres tempo, a lápis, num pedaço de papel de embrulho. Náo releias nem emendes: o que sair sai bem.

(...)

Adeus. Vou sonhar contigo. Teu Graciliano. Palmeira, 20 de janeiro de 1928 (Ramos, 1994, p. 92-94).

É esta uma carta de Graciliano Ramos à sua mulher. Tanto o eu quanto o tu estão explícitos neste texto. Está, assim, caracterizado um cenário de interação enunciativo, que identifica as interaçôes cotidianas. Há um detalhe no texto que precisa ser destacado: a personificaçâo do tu por Heloísa. Cria-se, nessa estratégia enunciativa de "invocar o leitor" (Maingueneau, 1996, p. 34), um efeito de proximidade intensificado pelo efeito de realidade. Se a interpelação do narratário por $t u$ implica um efeito de individualidade, a concretização desse $t u$ por um personagem específico resulta num efeito de personificação, de atenção exclusiva, isto é, de proximidade maior, quiçá, até, de intimidade e de cumplicidade. Esses dois últimos efeitos de sentido, intimidade e cumplicidade, emergem precisamente desta outra carta de Graciliano (p. 123), em que o signatário, em vez de chamar sua amada por Heloísa, a trata por Ló:

\section{Texto 4}

Ló: Todos nós vamos indo, com muitas saudades de você. Não lhe tenho escrito ultimamente porque não tenho nada para contar. Neste ramerrão de todos os dias parece que vou ficando estúpido. A última carta sua que recebi dizia que tudo por aí estava a contento e falava-me em sessenta mil-réis que v. ia pedir ao Antônio. Creio que v. ainda não tinha recebido uma que lhe mandei há alguns dias, com dinheiro. Se necessitar alguma coisa, avise-me para eu tomar aqui as providências.

(...)

Adeus, por hoje, Ló. Lembranças a seu Américo e às meninas. Um abraço para você. Beije por mim Lulu e Tatá. Gato. 1º. De setembro de 1932. (P. dos Índios). 
Fica evidente que Ló é uma forma afetiva de invocar Heloísa na intimidade. Trata-se de um procedimento autorizado ao marido e pessoas muito próximas do casal e de sua família. Fora desse círculo, o recurso causa estranheza, precisamente pelo fato de invadir o espaço reservado a íntimos e cúmplices. Destaquese também que Ló é uma interpelação própria das interaçôes face a face, isto é, das conversas. Ao empregá-la na carta, Graciliano empresta ao texto escrito um notável efeito de oralidade.

Nesse contexto interacional das relaçóes próximas ou íntimas, as pessoas costumam conversar, e quando se comunicam por escrito, transferem para o seu texto um simulacro desse cenário interativo, o qual vai determinar as que assim chamamos escolhas de segunda ordem, como o léxico, a sintaxe, por exemplo. Em nenhum dos dois últimos textos (3 e 4), há alguma palavra que não seja de uso corrente na fala cotidiana, sempre considerando, é claro, o conhecimento comum que os interlocutores têm um do outro.

Quanto à seleção lexical, queremos chamar particular atenção às características do texto 1 (Por que as girafas fedem?). Trata-se de um texto de divulgação científica para crianças. Todo ele, em seus diferentes aspectos de construção, é determinado por esse coenunciador leitor-criança, que emerge do texto como um destinatário que ainda não tem o domínio da língua em sua formulação conceptualmente escrita e, muito menos, em sua configuração no jargão científico. Do ponto de vista das escolhas lexicais, todas elas sintonizam com esse perfil de interlocutor em cujo contexto de vida predomina a interação pela fala. E quando a interação se estabelece pela escrita, ela costuma assumir as marcas da fala. Nesse sentido, há dois termos nesse texto que chamam particular atenção: "fedem" e "cheirinho". Por serem recursos de certa forma exclusivos da fala, eles intensificam o efeito de oralidade na escrita e, por isso, de proximidade entre narrador e narratário. Também as cartas de Graciliano (textos 3 e 4) registram escolhas lexicais que concorrem, pelas mesmas razóes, para a intensificação desses efeitos de sentido, como, por exemplo "Adeus", "Lembranças...", “...abraço...”, "Beije...”.

Do ponto de vista da sintaxe, nos três textos (1, 3 e 4), os períodos compostos por subordinação não passam da dimensão de duas orações, sendo a subordinada, em geral, uma oração adjetiva ou substantiva objetiva, eventualmente uma adverbial temporal. É essa também a característica comum das construçôes sintáticas dos enunciados das conversas.

Há ainda outros aspectos que se podem apontar nos textos para mostrar que as escolhas de segunda ordem estâo em sintonia com o cenário interativo que os configura. Embora não tenhamos o objetivo de fazer uma análise exaustiva dos textos, veja-se ainda o caso da pergunta retórica na primeira carta (texto 3) “... não é verdade?" Esse recurso encena uma interpelação ao interlocutor, como 
se, na sequência, lhe coubesse uma resposta, o que evidencia uma simulação de diálogo face a face. Esse procedimento pode-se também observar no texto 1 (Por que as girafas fedem?), já no título do texto, como também na passagem, ao final do primeiro parágrafo, "Mas você sabe por que as girafas fedem?" Por fim, criam ainda um forte efeito de oralidade em todos os textos analisados as reiteradas referências ao leitor, seja por você, $t u$, por formas oblíquas correspondentes (lhe, te, seu, teu) e marcaçôes verbais como, só para exemplificar, "lembre-se" (texto 1), "Não te preocupes" (texto 3), "avise-me" (texto 4).

Como dissemos, o nosso foco nestas reflexóes é o cenário de interação enunciativo. E, quando fizemos a distinção deste com o cenário enuncivo, apresentamos o texto 2. Com o narrador em terceira pessoa e o narratário implícito, este cenário náo convoca escolhas de segunda ordem que produzam efeitos de oralidade, mas, ao contrário, o cenário impôe escolhas que produzam efeitos de "escrituralidade", ou seja, escolhas próprias de textos tipicamente escritos. No texto 2 , emerge um enunciador configurado por seu saber científico que, de forma objetiva e analítica, se comunica sobre esse saber com um enunciatário não especificado, ao qual se atribui o domínio da linguagem própria para compreender o objeto da comunicação em curso. A relação entre narrador e narratário é, então, marcada pelo distanciamento, e todas as escolhas sintático-lexicais concorrem para a produção desse efeito de sentido. Formas que criassem efeitos de oralidade, em textos dessa ordem, produziriam, no mínimo, uma incoerência no que respeita à norma de uso dos diferentes níveis de linguagem.

E, em muitos casos - raramente em textos científicos -, quando se manifestam recursos linguísticos que produzem efeitos de oralidade em cenários enuncivos, o enunciador revela ter consciência desse fato, destacando-o no texto, como que dizendo ao leitor que se trata de uma formulação estranha para o cenário interativo em questão.

Observemos comparativamente passagens de editoriais de jornais, duas de editoriais da Folha de S. Paulo, e outras duas de editoriais do Agora São Paulo. ${ }^{8}$ Sabemos que editoriais são, reconhecidamente, textos configurados pelo cenário enuncivo. O primeiro jornal assume com rigor esse princípio. O segundo, no entanto, em diferentes ocasióes, o infringe. Ainda que raramente explicite no texto as marcas da enunciação enunciada (a relação eu/você), deixa implicitamente o leitor a perceber que o tom do editorial é de conversa, na medida em que o texto

8 Ambos os jornais são publicados pela mesma empresa jornalística Folha da Manhã.

Hilgert JG. Fundamentos para o estudo da oralidade na escrita 
é construído numa linguagem informal, supostamente em sintonia com a usada pelos presumidos leitores do jornal, em suas interaçóes cotidianas.

Vejamos as passagens: ${ }^{9}$

\begin{tabular}{|c|c|}
\hline Folha de S. Paulo & Agora São Paulo \\
\hline $\begin{array}{l}\text { Foi o oitavo "arrastão", desse tipo de que se } \\
\text { teve notícia na capital desde o início do ano } \\
(5.4 .2012)\end{array}$ & $\begin{array}{l}\text { Foi mais um arrastão na capital desde o } \\
\text { início do ano }(5.4 .2012)\end{array}$ \\
\hline $\begin{array}{l}\text { Embora o transporte metropolitano seja } \\
\text { da alçada estadual, o fato de o ex-governa- } \\
\text { dor tucano José Serra almejar a prefeitura } \\
\text { estimula críticas como as manifestadas pelo } \\
\text { pré-candidato petista, Fernando Haddad - } \\
\text { que se apressou a denunciar novamente um } \\
\text { "apagáo" dos transportes em São Paulo ( } 18 . \\
\text { 5. 2012). }\end{array}$ & $\begin{array}{l}\text { É natural que a oposição ataque o governo } \\
\text { do Estado, como fez o candidato petista à } \\
\text { prefeitura, Fernando Haddad. Para ele, esta- } \\
\text { ria acontecendo um apagáo nos transportes } \\
(18.5 .2012) \text {. }\end{array}$ \\
\hline
\end{tabular}

Quadro 1

Observem-se, na primeira coluna, as palavras "arrastão" e "apagão", respectivamente destacadas por aspas nos editoriais da Folha de S. Paulo, indicando, claramente, que são escolhas que não sintonizam com o caráter de "escrituralidade" de um editorial, ou seja, não cabem no contexto de um cenário enuncivo. Já, na segunda coluna, as mesmas palavras vêm sem destaque no Agora São Paulo, ou seja, são assumidas pelo enunciador como suas, em sintonia com os demais recursos convocados para a construção do texto, incluindo os de ordem sintática. Na Folha de S. Paulo, o destaque a elementos de oralidade fica praticamente reservado ao léxico, não se fazendo concessóes nesse sentido à sintaxe ou a outro recurso. E essa é uma característica geral da marcação da oralidade em textos propriamente escritos.

\section{CONSIDERAÇÓES FINAIS}

Em textos escritos, cabe considerar que não é a forma lexical em si nem a estrutura da frase por ela mesma que, em princípio, produzem efeitos de oralidade.

9 As passagens foram extraídas do corpus coletado por meu orientando, Marcelo Fleuri de Barros, para a sua Dissertação de Mestrado.

Hilgert JG. Fundamentos para o estudo da oralidade na escrita 
$\mathrm{Na}$ verdade, elas concorrem para produzir esse efeito, na medida em que o texto em que se inserem for configurado por um cenário de interação de proximidade. Portanto, é preciso focalizar a oralidade na escrita, tendo em conta, em primeiro lugar, a configuração do texto como um todo e, só depois, palavras, expressóes e estruturas isoladas. É evidente que há recursos presentes em textos escritos que, isoladamente, produzem efeitos de oralidade, na medida em que são manifestaçóes especificas da fala. Mesmo esses, porém, se apresentam, em geral, em cenários interativos de proximidade. Quando ocorrem em cenários interativos de distanciamento, a oralidade que lhes é inerente encontra sua coerência, no texto escrito, no efeito de estranhamento que produzem, assumindo, assim, diferentes funções argumentativas.

As cartas pessoais (entre familiares, amigos, conhecidos) são, evidentemente, um gênero textual modelar para verificar efeitos de proximidade e de oralidade, até por decorrência de relaçóes de proximidade da vida real, de ordem afetiva, existentes entre destinador e destinatário. Nem se espera, em princípio, outra forma de elaboraçáo textual. No entanto, os recursos usados em textos escritos para produzir efeitos de relaçóes de proximidade e efeitos de sentido de oralidade não cabem ser analisados a partir e em função das relaçóes extratextuais. A relação de fato entre destinador e destinatário não é pertinente nesse enfoque. O que importa é interpretar os referidos recursos enquanto estratégias discursivas usadas pelo enunciador para alcançar seus propósitos persuasivos.

\section{REFERÊNCIAS}

Bakhtin M. Marxismo e filosofia da linguagem. 14. ed. São Paulo: Hucitec; 2010.

Barros DLP. Interação em anúncios publicitários. In: Preti D (org.). Interação na fala e na escrita v.5. Sáo Paulo: Humanitas/FFLCH/USP; 2002. p. 17-44

Barros MF. Entre aspas : uma análise das funçóes metaenunciativas em editoriais dos jornais Agora São Paulo e Folha de S. Paulo [dissertação]. São Paulo : Universidade Presbiteriana Mackenzie ; 2014.

Blanche-Benveniste E. Le français parlé: études grammaticales. Paris: CNRS; 1990.

Editorial. Arrastão no Paraíso. Agora São Paulo. 5 abr. 2012.

Editorial. Choque no metrô. Agora São Paulo. 18 de mai. 2012. 
Editorial. Colisão no metrô. Folha de S. Paulo. 2012. Disponível em: http://www1. folha.uol.com.br/fsp/opiniao/43484-colisao-no-metro.shtml. Acesso em: 15 ago. 2014.

Editorial. Roubos e arrastóes. Folha de S. Paulo 5 abr. 2012. Disponível em: http:// wwwl.folha.uol.com.br/fsp/opiniao/35334-roubos-e-arrastoes.shtml. Acesso em: 15 ago. 2014.

Fiorin JL. Pragmática. In: Fiorin JL (org.). Introdução à linguística: princípios de análise. São Paulo: Contexto; 2003.

Hilgert JG (org.). A linguagem falada culta na cidade de Porto Alegre: diálogos entre dois informantes. Vol. III. Florianópolis: Insular; 2009.

Kerbrat-Orecchioni C. L' énonciation: de la subjectivité dans le langage. Paris: Armand Colin; 1980.

Koch P, Oesterreicher W. Gesprochene Sprache in der Romania: Französisch, Italienisch, Spanisch. Tübigen: Niemeyer ; 1990.

Koch P, Oesterreicher W. Sprache der Nähe-Sprache der Distanz. Romanistisches Jahrbuch. 1985; 36:15-43.

Koch P, Oesterreicher W. Funktionale Aspekte der Schriftkultur. In: Günther H, Ludwig O (eds.). Schrift und Schriftlichkeit. Berlim/Nova Iorque: Walter de Gruyter. 1994; 1: 588-604.

Koch P, Oesterreicher. W. Zeitschrift für germanistische Linguistik. 2007; 35: 346-375.

Lopes G. Por que as girafas fedem? [site]. 2003. Disponível em: <http://chc.cienciahoje. uol.com.br/por-que-as-girafas-fedem/>

Maingueneau D. Cenas da enunciação. Curitiba: Criar Ediçôes; 2006.

Marcuschi LA. Da fala para a escrita: atividades de retextualização. São Paulo: Cortez; 2001.

Ramos G. Cartas. Rio de Janeiro: Record; 1994. 
Tatit L. A linguagem do texto. In: Fiorin JL (org.). Introdução à linguística: objetos teóricos. Vol. 1. São Paulo: Contexto; 2002. p. 187-209. 